\title{
BUDDHIST STELE OF SWAT VALLEY: POINT CLOUD ANALYSIS AND INTERPRETATION
}

\author{
E. Faresin ${ }^{1 *}$, G. Salemi ${ }^{1}$ \\ ${ }^{1}$ Dipartimento dei Beni Culturali: archeologia, storia dell'arte, del cinema e della musica. Università di Padova, \\ Piazza Capitaniato, 7, 35139 Padova, Italy.giuseppe.salemi@unipd.it; emanuela.faresin@unipd.it
}

\section{Technical Commission II}

KEY WORDS: 3D Model, Structured Light, Surface Analysis, Point Cloud Interpretation, Carved Stone

\begin{abstract}
:
With recent advancements on 3D sensors and cloud computing, high-speed, high-accuracy 3D measurement at micrometer level have been increase by scientists community and digital humanities researchers.

The methodology proposed in this project aims to test some of the algorithms used in remote-sensing to the Buddhist sculptures from Swat Valley (Pakistan); these algorithms use high-resolution topographic data to identify, from DEMs, specific features like valleys, ridges, peaks, pits or surface anomalies.

In the carved stone, the surface is analysed like a landscape, where carved areas are valleys bordered by slopes and crests. One of the simplest tools, the commonly used analytical hill-shading, which simulates artificial illumination on the DEM surface, is based on the same principle as the use of an oblique light source to highlight incisions in classic photography. Other families of algorithms that can be divided into three main groups (Slope and Curvature, Local Relief Model and Sky View Factor, Positive and Negative Openness and Geomorphons) are tested here.
\end{abstract}

\section{INTRODUCTION}

The Swat valley has always been considered a vital nerve center of Gandhara art, but due to the unfavourable conditions, this artistic phenomenon has long been almost ignored or underestimated. Systematic archaeological investigations have been carried out there since 1956 by the Italian Archaeological Mission in Pakistan (MAI) of the IsMEO/IsIAO in close collaboration with the Department of Archaeology \& Museums, Govt. of Pakistan (DOAM). (Filigenzi, 1999). A special place is occupied by the Buddhist rock sculptures that flourished in Swat in the seventh to eighth centuries.

Nowadays, this cultural heritage is jeopardised by human degradation related to mass tourism, developmental progress, such as road and infrastructure building, etc., climate change can also drastically accelerate its fading. Over the last three decades, there has been a technological revolution in computer vision for $3 \mathrm{D}$ acquisition and its application to real-world objects (Remondino, Rizzi, 2010; Domingo et al., 2013; Soler et al., 2017), contemporary with major advances in mathematical treatment (Petrie, Kennie, 1987). Such advances could well be advantageously applied to extensive rock art documentation. Non - contact 3D scanners based on either structured light or laser beam (Szeliski, 2010) are costly and better adapted to small and medium objects. Moreover they have been used successfully for rock art acquisition (Monna et al., 2018).

This project starts with the 3D survey of a group of 17 stele preserved at the Swat Archaeological Museum of Saidu Sharif (Ashraf Khan, 1993). The methodology proposed aims to test some of the algorithms used in remote-sensing to the stele num. 17; these algorithms use high-resolution topographic data to identify, from DEMs, specific features like valleys, ridges, peaks, pits or surface anomalies. In the carved stone, the surface is analysed like a landscape: carved areas are valleys bordered by slopes and crests. The algorithms tested in this project can be divided into three main groups: Slope and Curvature, Local Relief Model and Sky View Factor, Positive - Negative Openness and Geomorphons (Monna et al., 2018).

The aim is to evaluate the ability of algorithms to highlight specific details and profiles of single iconographic features in order to increase the capacity to extract artistic informations. Two different open source GIS enviroments were chosen to process very large data set, overcoming available RAM management problems.

\section{MATERIAL AND METHODS}

\subsection{Gandhara Art}

Buddhist rock sculptures, flourished in Swat in seventh to eighth centuries. In a period when the ancient splendour was already on the wane before becoming irrevocably overshadowed by Islam, Buddha and bodhisattva figures started populating numerous paths in the form of carved reliefs on rock walls, isolated boulders and stele set in the ground. This figurative culture is called "Gandhara art". All the sculptures are located, with very few exceptions, along the left tributaries of the Swat river, where the urban settlement is favoured by natural conditions and is often connected to the sacred areas by an adequate distance. The general appearance of rock sculpture is characterized by a limited iconographic repertoire and by a general figurative concept, with the image treated as an icon and displayed in its specific attributions, without references to contingent actions or situations. The first general observation is that the whole set of sculptures forms an all-male pantheon. The figure of Avalokiteśvara / Padmapānị ("the lotus bearer") occupies a position of absolute predominance (Filigenzi, 2003). The classification of rock sculptures, in terms of stylistic and iconographic criteria, is hampered by the objective conditions of

* Corresponding author 
poor conservation. The damage caused by atmospheric agents has been further aggravated by iconoclasm acts. The least seriously damaged is the figure of Padmapānị: its position of absolute predominance guarantees an easy recovery of the missing elements making comparisons within the same typological group. The other bodhisattva figures are more damaged: important iconographic details, such as the specific shape of an attribute or a headdress, are erased. The fact that these subjects are less frequent, makes a precise interpretation of the images more difficult (Filigenzi, 1996; Filigenzi, 2000)

Stele n. 17 was chosen as case study for the richness of details and for the best state of conservation. It represents a male figure, with nimbus with circle and flaming edge, in padmāsana on throne with lions, supported by a double lotus corolla, under a canopy, flanked by a pair of smaller haloed figures, standing three quarters on towards the central figure on lotus flowers with upturned petals and short stem emerging from the throne.

The central figure is dressed as a bodhisattva; of the minor figures, the right hand one, female, holding an attribute in both hands; the left hand figure, male, holding an attribute with the palm of the left hand. The throne is covered with a decorated drape. The lions, crouching frontally with crossed forepaws, have globe-shaped eyes and long mane with symmetrical curls; below the lotus, in the centre, there are three figuration elements; a border in relief runs round the bottom of the figuration. The canopy is decorated with a border in relief and inside by undulating ribbons (Figure 1) (Filigenzi, 2015).

\subsection{D High Resolution Model}

The available technologies and methodologies for digital recording of archaeological sites and objects are really promising and the whole heritage community is trying to adapt these approaches for fastest, detailed and easy 3D documentations (Pavlidis, 2007; Gomes et al., 2014; Younan, Treadaway, 2015; Rossi et al., 2019).

The structured light technique belongs to the active methods and uses a projection device to actively project structured patterns. This scene is then captured by a typical digital image detector and processed in order to reconstruct the geometry from the deformations of the pattern in the digital image. This method is accompanied by texture acquisition and can lead to very impressive results in terms of accuracy (Zhang, 2018; Salvi et al., 2010). The 3D model is a faithful and measurable digital representation of the object through the representation of its morphological and morphometric characteristics (BentkowskaKafel, MacDonald, 2018). The stele has a rather flat relief with few undercuts. The complete stele scan produced 41 range maps with a good level of overlap and a micrometer $(0.0040 \mathrm{~mm})$ accurate geometric level. The data collected by the scans are $X$, $Y, Z$ coordinate triplets of each single point analysed. Data processing with Optical RevEng 2.4 SR 8 Pro software followed the standard steps of the 3D scanning pipeline (Vrubel et al., 2009). The global alignment is the result of the 56592289 points alignment with a standard deviation of $0.0275 \mathrm{~mm}$. Through the meshing phase the amount of points produced a mesh of 2418850 triangles (Table 1 ).

During the editing phase, no fill holes procedure was applied. This is possible before of the high number of scans despite of the dimension of the stele $(94 \times 50 \mathrm{~cm})$ and to the high overlapping, in order to obtain a very high resolution model (Figure 2).

Four different datasets were produced to take in account the effect of the progressive decimation for the surface analysis (Table 2).
The instrument used for the acquisition is Cronos Dual, a structured light system by Open Technologies, with an accuracy of $10 \div 40 \mu \mathrm{m}$ and a camera resolution of $2 \times 1.3$ MPixels.
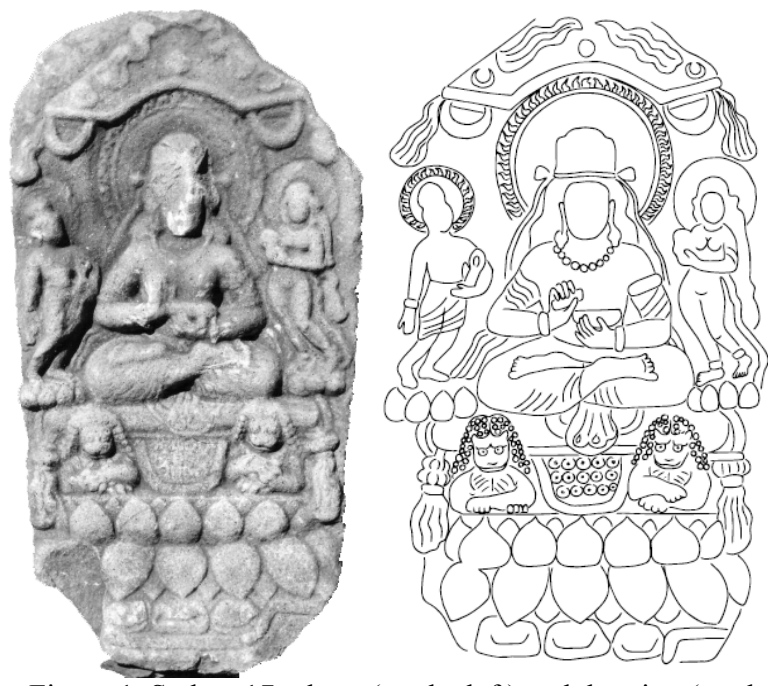

Figure 1. Stele n.17: photo (on the left) and drawing (on the right). Seated siddha (?) with attendants. Irregularly ovalshaped stele, with straight cut on the sides.
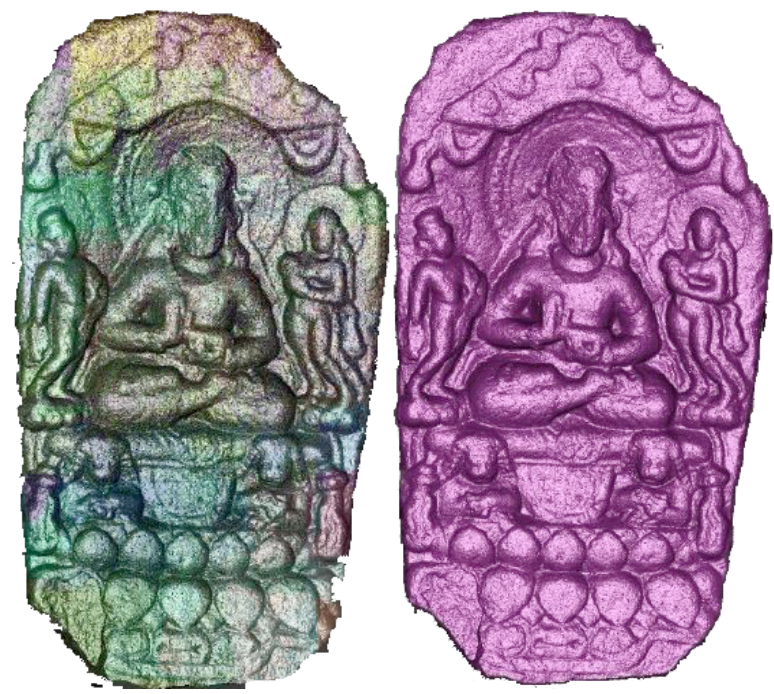

Figure 2. Stele n.17: high density point cloud (on the left) and $3 \mathrm{D}$ high resolution mesh (on the right).

\begin{tabular}{|l|c|}
\hline \multicolumn{2}{|c|}{ Stele n. 17 } \\
\hline Number of scans & 41 \\
\hline Deviation standard & $0,03 \mathrm{~mm}$ \\
\hline Number of points & 56592289 \\
\hline Number of triangles & 2407900 \\
\hline
\end{tabular}

Table 1. Stele n. 17 descriptive parameters for the global dataset.

\begin{tabular}{|c|c|c|}
\hline Decimation & N. Triangles & MB \\
\hline $100 \%$ & 2418850 & 171,166 \\
\hline $75 \%$ & 1814136 & 86,723 \\
\hline $50 \%$ & 1209425 & 57,600 \\
\hline $25 \%$ & 1197345 & 40,897 \\
\hline
\end{tabular}

Table 2. Progressive decimated datasets for surface analysis. 


\section{INDICES FOR SURFACE ANALYSIS}

The methodology proposed here aims to evaluate some of the numerous algorithms used in remote sensing, more particularly those using high-resolution topographic data (like LiDAR data) to identify, from DEMs, specific features in landscapes (Hesse, 2010; Štular et al., 2012; Devereux et al., 2008).

The goal is to test the potentiality of the algorithms to highlight the profiles of the single subjects in order to increase the knowledge on the iconographic and iconological details and on preservation state.

The software used for the surface analysis are SAGA GIS 2.0.0 (System for Automated Geoscientific Analysis) and GRASS GIS 7.6 (Geographic Resources Analysis Support System).

The algorithms tested are: Slope, Profile Curvature, Local Relief Model, Sky View Factor, Positive and Negative Openness and Geomorphons.

- Slope: is defined as the maximum rate of change in elevation between each cell and its neighbours, also known as maximum down hill gradient (Longley et al., 2005). It is obtained from the first derivative of the DEM. It depends on the resolution of the DEM, and can be dramatically impacted by the presence of noise blurring the signal, so that prior smoothing may be required.

- Profile Curvature: is the second derivative of the DEM in a direction parallel to the maximum slope (De Smith et al., 2007). It varies between positive values for convex and negative for concave shapes, while a zero value denotes a planar surface. High slope values are expected along the slope of the incised part, while positive curvatures should identify rims, and negative curvatures indicate foot slopes.

$$
K_{t g}=\frac{\frac{\delta^{2} z}{\delta x^{2}}\left(\frac{\delta z}{\delta x}\right)^{2}-2 \frac{\delta^{2} z}{\delta x \delta y} \frac{\delta z}{\delta x} \frac{\delta z}{\delta y}+\frac{\delta^{2} z}{\delta y^{2}}}{p q^{1 / 2}}=K_{p t}\left(\frac{p}{q}\right)^{1 / 2}
$$

where:

$$
\begin{aligned}
& p=\left(\frac{\delta z}{\delta x}\right)^{2}+\left(\frac{\delta z}{\delta y}\right)^{2} \\
& q=1+p
\end{aligned}
$$

- Local Relief Model (LRM): it is the less distorted representation of the small-scale topographical features and it more likely reflects the relative heights and depth of these features than the surrounding landscape (Hesse, 2010).

- Sky View Factor (SVF): is an alternative method of hill-shading to detect features from LiDAR raster data. It measures the portion of the hemispheric sky limited by reliefs, seen from a given point. The SVF is computed by discretizing the space in $n$ compass directions, and seeking the vertical angle starting from the horizon from which the sky becomes visible (Zakšek, et al., 2011).

$$
S V F=\frac{\sum_{1=1}^{n} \sin \gamma i}{n}
$$

- Openness: it depicts the degree of dominance or enclosure of a location on an irregular surface. The positive openness is equivalent to the average zenith angle of all established horizons, while the negative openness is based on nadir angles. The zenith or the nadir angles are determined for each cell, as well as the characteristics within the search radius, along the eight directions of the compass. The positive openness highlights the convexities (ridges, peaks), while the negative openness the concavities (valleys) (Doneus, 2013; Yokoyama et al., 2002).

$$
\begin{aligned}
& \alpha_{R}=\frac{\alpha_{0}^{R}+\alpha_{R}^{45}+\ldots+\alpha_{R}^{315}}{8} \\
& \beta_{R}=\frac{\beta_{0}^{R}+\beta_{R}^{45}+\ldots+\beta_{R}^{315}}{8}
\end{aligned}
$$

- Geomorphons: are used for the classification and for mapping terrain elements from a DEM based on the principle of model recognition. They are ternary schemes that serve as archetypes of a particular morphology of the terrain, fundamental microstructures of landscape and can be reduced to 10 common forms of land: peak, ridge, shoulder, spur, slope, hollow, slope, valley, pit and plain (Stepinski, Jasiewicz, 2011; Jasiewicz, Stepinski, 2013; Libohova, 2016).

\section{RESULTS AND DISCUSSION}

The use of algorithms makes possible to confirm the hypotheses elaborated in previous iconographic studies, to propose new hypotheses based on the identification of new details and to clarify the conservative state of the stele. Slope analysis provides a clearly legible image that highlights the details of the stele and reveals the characteristics of the irregular surface (Figure 3a). Profile curvature generates a flat and not clearly legible image, which better highlights the grooves of the engraving and clearly delineate even the smallest details of the stele (Figure 3b). Local Relief Model (LRM) proves to be suitable for the display of very low topographic features independent of their position (ridge, valley, slope) and their direction (if linear). It is useful to better highlight the engraving furrows and the smallest details of the stele. Nevertheless it doesn't allow to recognize the characteristics of the uneven surface that tend to homogenize with the rest of the stele (Figure 3c). Sky View Factor (SVF) correctly reveals the carving, the protruding parts that are on the rather flat surface; in particular, the border of the figure, and the characteristics of the irregular surface. Nevertheless, referring to a horizontal plane, it looses details, the features are not well defined and tend to be confused with the rest of the sculpture (Figure $3 \mathrm{~d}$ ). The positive and negative openness, enhances the deepest parts of the sculpted areas. In case of particularly well preserved reliefs, it offers a clear distinction between the iconographic features and the surrounding surface. The algorithm highlights both the higher and lower parts, but it is not very efficient with particularly damaged stele or with details that are difficult to distinguish (Figure 3e). 

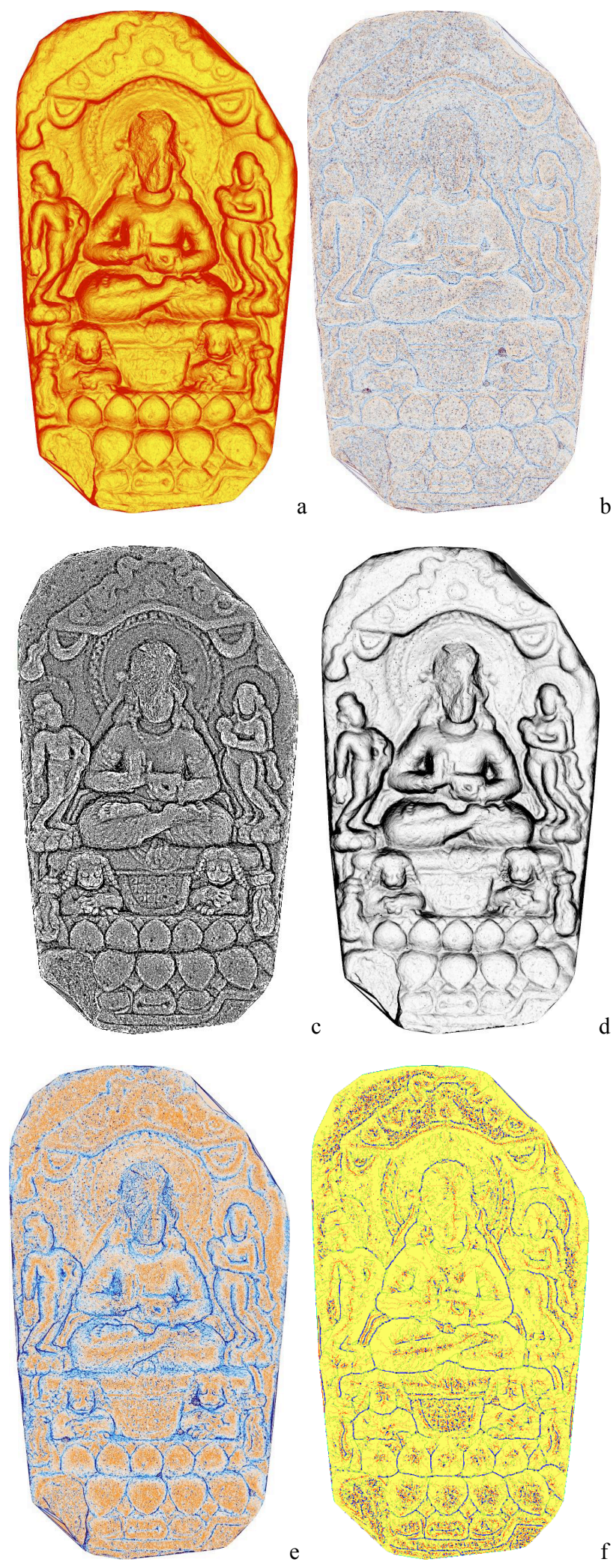

d

Figure 3. Stele n.17: Slope (a), Profile Curvature (b), Local Relief Model (c), Sky View Factor (d), Positive Openness (e) and Geomorphons (f).

The use of geomorphons has shown how the algorithm is able to adapt well to the surface, highlighting the single features, although not with remarkable accuracy. The best results concern the conservative state of the stele and the surface treatment.
The chipped areas, which can already be guessed from the 3D model, are clearly circumscribed by the algorithm, which also allows us to identify abrasions, not clearly distinguishable from the $3 \mathrm{D}$ model. Where the surface is damaged, the algorithm shows various and different "soil shapes", providing a "dotted" image, without creating any specific design.

Although the processing of the material was reduced to a minimum and the surface always maintains a rough profile, it is possible to identify a different surface treatment in the border areas between figures and background. The worked areas are smoother and with a greater slope, while the unworked ones, left in their natural state, present a varied situation of soil forms, which emphasizes a greater surface roughness, which is distinguished by the "dotted" section of the abrasions (Figure 3f). Table 3 shows the time computing spent to process the single index.

\begin{tabular}{|c|c|}
\hline \multicolumn{2}{|c|}{ Processing time (mm:ss) } \\
\hline Slope & $00: 02$ \\
\hline Profile curvature & $00: 02$ \\
\hline Openness & $00: 03$ \\
\hline Sky View Factor & $00: 34$ \\
\hline Local Relief Model & $09: 34$ \\
\hline Geomorphons & $01: 39$ \\
\hline
\end{tabular}

Table 3. Processing time for surface analysis indices.

\section{CONCLUSIONS}

The focus of this contribution is the interdisciplinary. The synergy between the archaeological field and new technologies has allowed to start a new phase of studies on the art of Gandhara in the Swat Valley.

The main goal was to use the virtual model and the point cloud analysis for an increment of knowledge on the archaeological heritage.

The structured light 3D methodologies has allowed to produce $3 \mathrm{~d}$ models of the stele with a micrometer resolution. These are the starting point for the surface analysis and further investigations that may be carried out in the future. Born for engineering areas, these technologies, prove to be useful and show their full potential event in the archaeological field.

The application of GIS software in landscape archaeology studies, has a consolidated tradition, while applications to single objects, such as sculptures or other artefacts, are more recent and still in the experimental phase. The use of the algorithms was necessary to obtain as much data as possible and to evaluate their specific effectiveness.

Considering the heterogeneity of the material, it can be reasonably stated that each algorithm has contributed to defining the individual stele. It is possible, however, for this group of stele, to express a preference towards some algorithms that have proved to be more performing: Slope, Local Relief Model (LRM) and Sky View Factor (SVF) appear to have made a major contribution to investigations by offering more new elements to the study of individual stele (Appendix A).

More than simply complementing the usual techniques, our 3D modelling approach opens up new perspectives. The combination of drawings with the image of the surface analysis is proposed as a new reference for rock art documentation. In addition to the traditional $2 \mathrm{D}$ archaeological documentation, the 3D high resolution models produced can easily be used to compute volumes, measure distances. The 3D models provide information for degradation surveys, and can be exchanged between researchers, shared with the public on the web, and printed or integrated into 3D virtual scenes. 


\section{REFERENCES}

Ashraf Khan, M., 1993: Gandhara Sculptures in the Swāt Museum (Saidu-Sharif: 1993).

Bentkowska-Kafel, A., MacDonald, L., 2018: Digital techniques for documenting and preserving cultural heritage. ISD LLC.

Devereux, B. J., Amable, G. S., Crow, P., 2008: Visualisation of LiDAR terrain models for archaeological feature detection. Antiquity, 82(316), 470-479.

De Smith, M. J., Goodchild, M. F., Longley, P., 2007: Geospatial analysis: a comprehensive guide to principles, techniques and software tools. Troubador publishing ltd.

Domingo, I., Villaverde, V., López-Montalvo, E., Lerma, J. L., \& Cabrelles, M., 2013: Latest developments in rock art recording: towards an integral documentation of Levantine rock art sites combining 2D and 3D recording techniques. Journal of Archaeological Science, 40(4), 1879-1889.

Doneus, M., 2013: Openness as visualization technique for interpretative mapping of airborne lidar derived digital terrain models. Remote sensing, 5(12), 6427-6442.

Filigenzi, A., 1996: Pakistan, NWFP - Rilievi rupestri nello Swat, Bollettino di Archeologia, 41-42 (1996), 271-284.

Filigenzi, A., 1999; Il Bodhisattva Maitreya nell'arte rupestre dello Swat. Appunti sull'iconografia e sul culto del Buddha venturo, Conferenze Ismeo, 13 (ISIAO, 1999).

Filigenzi, A., 2000: Wisdom and Compassion: Iconography and Iconology of Avalokiteśvara/Padmapānị. Annali dell'Istituto Universitario Orientale di Napoli, 60-61(2000), 247-264.

Filigenzi, A., 2003: A Vajrayanic Theme in the Rock Sculpture of Swat, eds G. Verardi and S. Vita Buddhist Asia 1. Papers from the First Conference of Buddhist Studies Held in Naples in May 2001, (2003), 37-55.

Filigenzi, A., 2015: Art and Landscape (Vol. 462, p. 352). Verlag der Österreichischen Akademie der Wissenschaften.

Gomes, L., Bellon, O. R. P., Silva, L., 2014: 3D reconstruction methods for digital preservation of cultural heritage: A survey. Pattern Recognition Letters, 50, 3-14.

Hesse, R., 2010: LiDAR-derived Local Relief Models - a new tool for archaeological prospection. Archaeological Prospection, 17 (2010), 67-72.

Jasiewicz, J., Stepinski, T. F. 2013: Geomorphons-a pattern recognition approach to classification and mapping of landforms. Geomorphology, 182, 147-156.

Libohova, Z., Winzeler, H. E., Lee, B., Schoeneberger, P. J., Datta, J., Owens, P. R., 2016: Geomorphons: Landform and property predictions in a glacial moraine in Indiana landscapes. Catena, 142, 66-76.

Longley, P. A., Goodchild, M. F., Maguire, D. J., Rhind, D. W., 2005: Geographic information systems and science. John Wiley \& Sons.
Monna, F., Esin, Y., Magail, J., Granjon, L., Navarro, N., Wilczek, J., Saligny L., Couette S., Dumontet A., Chateau, C., 2018: Documenting carved stones by 3D modelling-Example of Mongolian deer stones. Journal of Cultural Heritage, 34, 116128.

Pavlidis, G., Koutsoudis, A., Arnaoutoglou, F., Tsioukas, V., Chamzas, C., 2007: Methods for 3D digitization of cultural heritage. Journal of cultural heritage, 8(1), 93-98.

Petrie, G., Kennie, T. J. M., 1987: Terrain modelling in surveying and civil engineering. Computer-aided design, 19(4), 171-187.

Remondino, F., Rizzi, A., 2010: Reality-based 3D documentation of natural and cultural heritage sites techniques, problems, and examples. Applied Geomatics, 2(3), $85-100$.

Rossi, C., Pettenò, E., Emanuele, S., Faresin, E., Salemi, G., Mariotti, M., Molin, G., 2019: A lead-framed glass mirror from a Roman woman's grave in Padua/Patavium (north-eastern Italy)-investigating its function and production with a multidisciplinary approach. Journal of Cultural Heritage, 38, 94-105.

Salvi, J., Fernandez, S., Pribanic, T., Llado, X., 2010: A state of the art in structured light patterns for surface profilometry. Pattern recognition, 43(8), 2666-2680.

Soler, F., Melero, F. J., \& Luzón, M. V., 2017: A complete 3D information system for cultural heritage documentation. Journal of Cultural Heritage, 23, 49-57.

Stepinski, T. F. Jasiewicz J., 2011: Geomorphons - a new approach to classification of landforms, Proceedings of Geomorphometry, 2011, 109-112.

Štular, B., Kokalj, Ž., Oštir, K., \& Nuninger, L., 2012: Visualization of lidar-derived relief models for detection of archaeological features. Journal of Archaeological Science, $39(11), 3354-3360$

Szeliski, R., 2010: Computer vision: algorithms and applications. Springer Science \& Business Media.

Vrubel, A., Bellon, O. R., Silva, L., 2009: A 3D reconstruction pipeline for digital preservation. In 2009 IEEE Conference on Computer Vision and Pattern Recognition (pp. 2687-2694). IEEE.

Yokoyama, R., Shirasawa, M., Pike, R. J., 2002: Visualizing topography by openness: a new application of image processing to digital elevation models. Photogrammetric engineering and remote sensing, 68(3), 257-266.

Younan, S., Treadaway, C., 2015: Digital 3D models of heritage artefacts: Towards a digital dream space. Digital Applications in Archaeology and Cultural Heritage, 2(4), 240-247.

Zakšek, K., Oštir, K., Kokalj, Ž., 2011: Sky-view factor as a relief visualization technique. Remote sensing, 3(2), 398-415.

Zhang, S., 2018: High-speed 3D shape measurement with structured light methods: A review. Optics and Lasers in Engineering, 106, 119-131. 
APPENDIX A
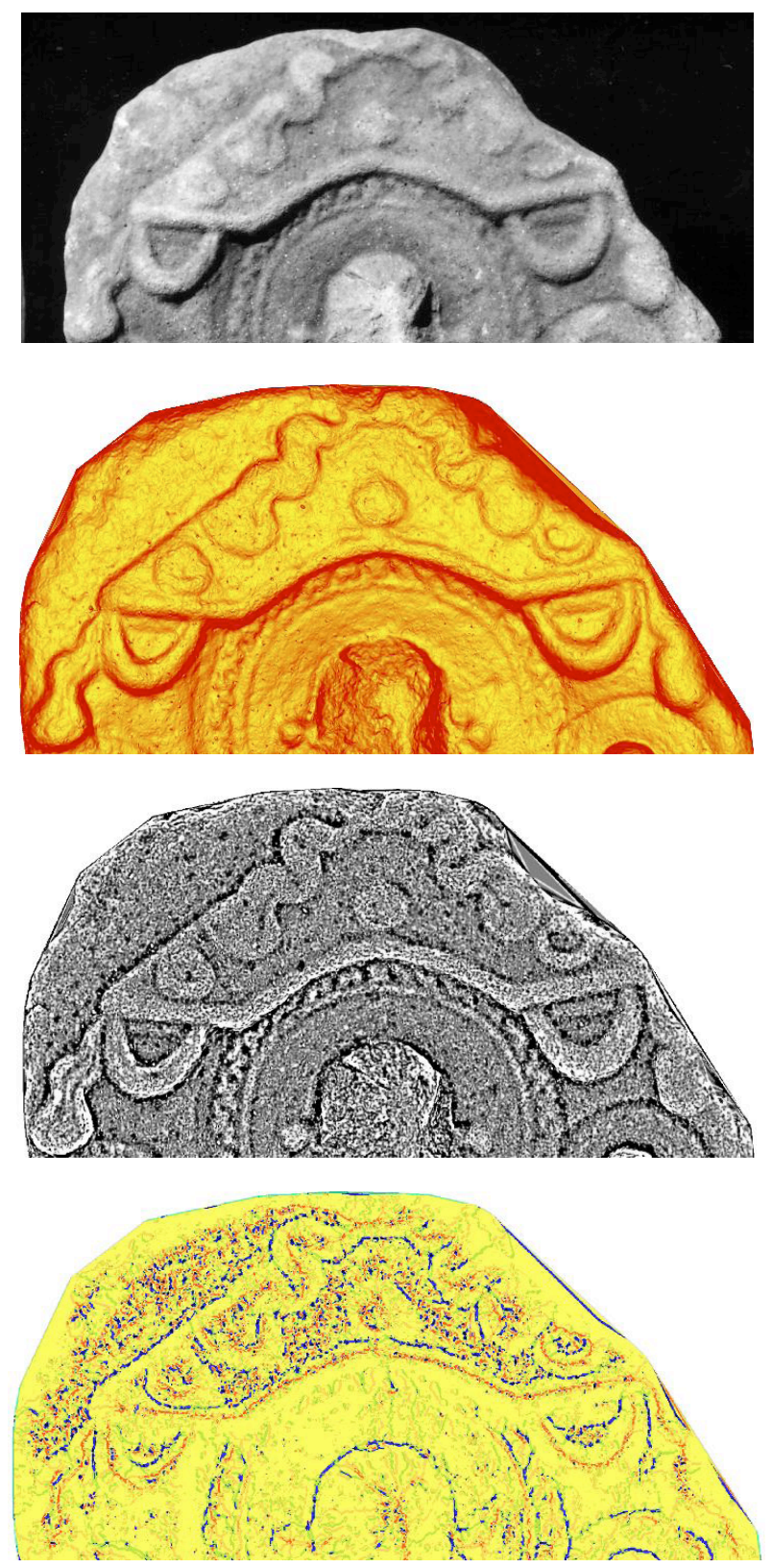

In Slope analysis and Local Relief Model it is possible to see the lower edge of the canopy, which consists in rounded strip that frames the upper part of the central figure. At the lower corners of the canopy and in the center of the curvilinear section, three circular shapes, similar to the rosettes are identified. Moreover, it is possible to see some dots in correspondence of the imperfections of the stone. With geomorphons, the upper part of the canopy its characterized by many points of different colours and this indicates different "soil" shapes and identify surface corrosion.
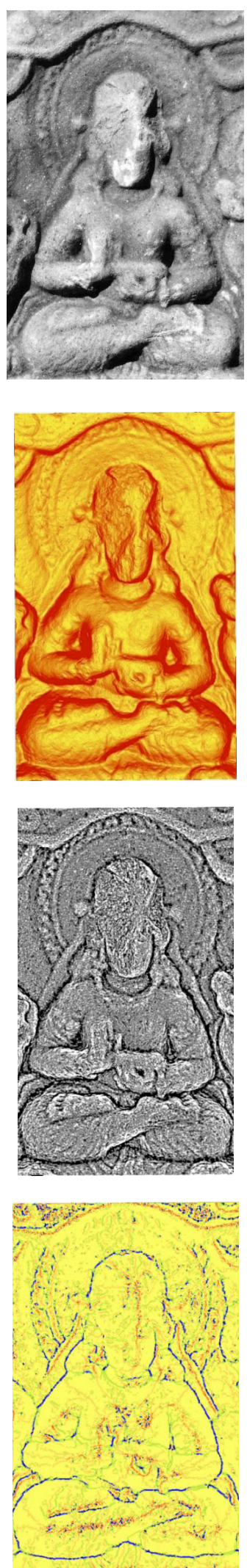

The subject wears a necklace and bracelets at the wrists and shoulders. The feet have the plant upwards and it is possible to distinguish the toes, rendered in a particularly realistic way in Slope analysis and Local Relief Model. From the geomorphons analysis a good state of preservation of the central figure is evident. 

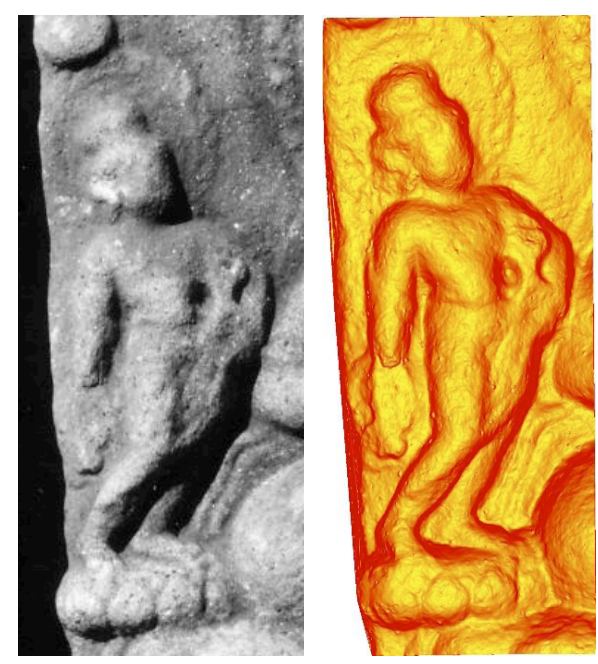

In the male figure on the left it is possible to identify the flaming halo from Local Relief Model and distinguish the hair gathered in a high bun.
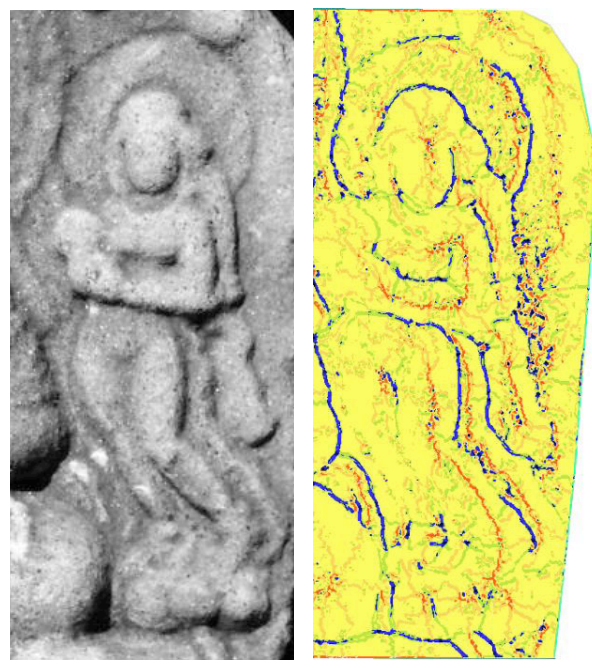

The female figure on the right has a cap like hair. At the height of the ears the hair, or wavy ornamental bandages, descend to the elbow. The geomorphons don't show any particular superficial damage: the area is well preserved and legible, although some details are not yet completely clear.
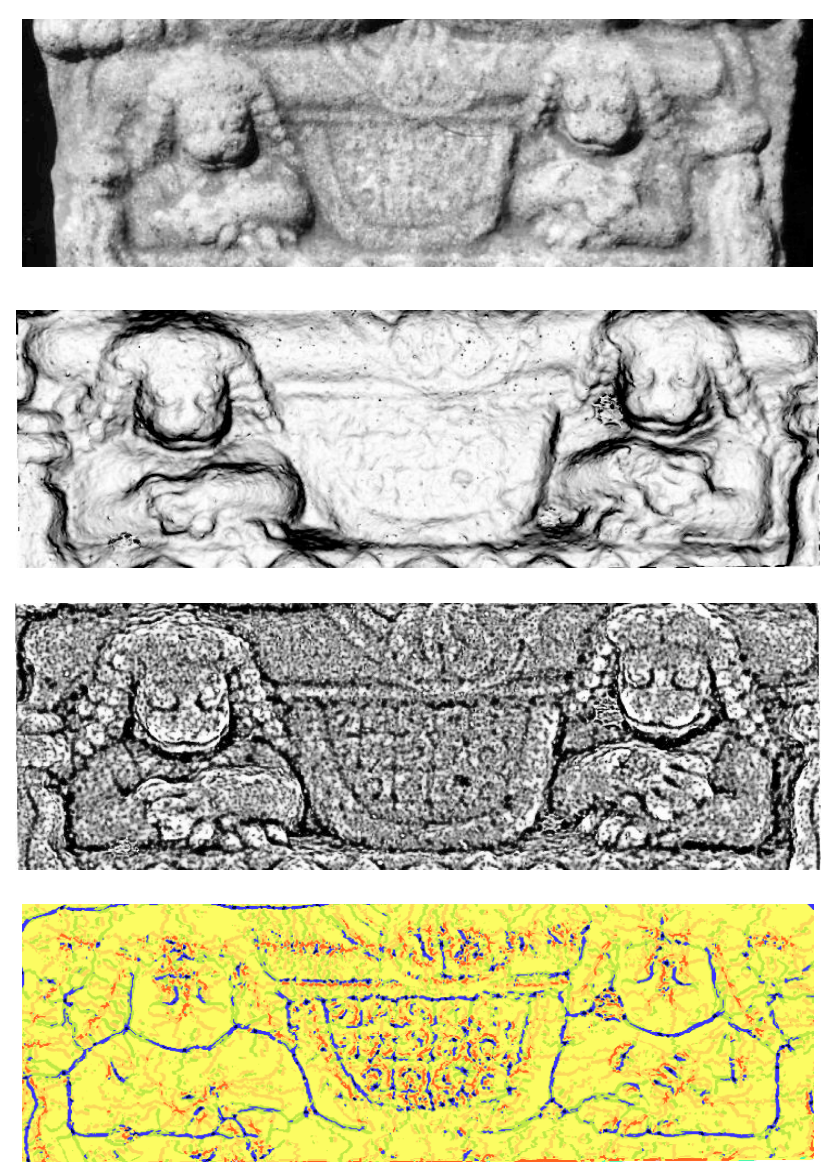

The throne is supported by two lions clearly visible in the Sky View-Factor which highlights better the volumes. The lions are crouched with the front legs crossed in front of the chest; the mane is made with symmetrical curls and this give to the animals an human aspect. Between the lions a strip of woven, which encloses a decoration of rosettes on several overlapping lines, as clearly visible from Local Relief Model and geomorphons

Moreover, geomorphons don't show any particular surface damage. The area is well preserved and legible. 